\title{
Charismatiese bewegings
}

\author{
H G van der Westhuizen (Piet Plessis) ${ }^{1}$ \\ Emeritus-professor: Hervormde Teologiese Opleiding
}

\begin{abstract}
Charismatic movements

There are a few main types of charismata: general charisma, individual and pecultar charismata. The first category is for all believens, and comprises prophetic, priestly and kingly charismata. The thind category of charismata consists of the church offices. Charismatic movements concentrate on the second category, namely the individual charismata. Persons with these charismata are recognized by their specific conversion and baptismal with the Holy Spirit, their own sort of liturgy, their biblical fundamentalism, by their concept of Pneumamonism, as well as by their religiousness which is not church bound.
\end{abstract}

Prof S J Botha se artikel oor Campus Crusade: Inhoud en metodes bevraagteken (Botha 1985:9), het nogal destyds heelwat positiewe maar selfs negatiewe reaksie uitgelok. Omdat prof Botha altyd baie keurig en noukeurig die Kerk se standpunt geformuleer het oor sake, en daarom ook oor charismatiese sake, dra ons hierdie artikel aan hom op.

Waar prof Schalk Botha, wat sedert 1980 tot 1993 saam met skrywer 'n dosent by die Hervormde Teologiese Opleiding was, en daarna as hoogleraar aan die Universiteit van Pretoria aangestel is, nou na twee dekades aan die einde van sy formele akademiese lewe gekom het, word met hierdie bydrae dank en waardering vir sy werk in die Kerk uitgespreek.

\footnotetext{
1 Prof ar H G van der Westhuizen (BA, DD) is emeritus-professor van die Hervormde Teologiese Opleiding (HTO) te Hammanskraal. Dosente van HTO is geakkrediteerde personeellede van die Hervormde Teologiese Kollge, Universiteit van Pretoria.
} 


\section{CHARISMATA}

Die woord charisma wat van charis = guns, genade, kom, en in die Nuwe Testament genadegawe beteken, verwys na alles wat die Heilige Gees in die ryk van die herskepping uit die volheid van Christus neem om aan die kerk te skenk (Grosheide 1957:148). Die woord charisma kom glad nie in die Evangelies of Handelinge voor nie. Dit kom net 1 keer in 1 Petrus 4:10 voor, en verder net by Paulus en wel 26 keer (Bloem 1967:122, 123).

Die verklaring hiervoor lê in die feit dat daar 'n onderskeid is tussen die Heilige Gees as gawe (dorea - Hand 2:38; 8:20; 10:45; 11:17) en die gawes van die Heilige Gees (charismata). Eers nadat die Heilige Gees as gawe aan die kerk gekom het, gee die Heilige Gees gawes aan die kerk (Joh 7:39). Die Evangelies en Handelinge handel oor die handele van die Heilige Gees (Bloem 1967:127).

Daar is 'n paar hooftipes van charismata: algemene charisma, individuele charismata en besondere charismata.

Die algemene charisma is aan alle gelowiges geskenk. Dit is die verlossing en ewige lewe (Rom 5:15-17; 6:23). Met hierdie algemene genadegawe is dit inderdaad anders as met die misdaad - dit het nie die dood tot gevolg nie, maar is die ewige lewe. En dit kom byvoorbeeld nie deur die bloedlyn van die tweede Adam af nie. Jesus was nie getroud nie en het nie kinders verwek nie. Die algemene genadegawe kom verbondsmatig vir baie oorvloedig. Die drie kenmerke van die ware kerk, die suiwere prediking, die regte sakramente, die getroue tug, is ingesluit in die atgemene charisma. Die kerk wat die gemeenskap van die heiliges is, is dus reeds die charismatiese beweging van God.

Die tweede groep genadegawes kan die individuele genadegawes genoem word (Du Toit 1979:190). Die ontvanger beskik egter nooit daaroor as sy eie nie (1 Kor 12:11). Dit bly aan die Gewer verbonde (Bloem 1967:128). Die bekender benaming vir die individuele genadegawes, is besondere genadegawes. Om twee redes veral verkies ook ek om hierdie benaming nie vir die individuele genadegawes te gebruik nie. Eerstens kan die kwalifikasie "besondere" misverstaan word "asof dit hier om iets heel spesiaals gaan, iets dramaties, iets sensasioneels wat die ontvangers daarvan tot 'n heel besondere groep verhef. Hierdie soort ding is vir die kerk van Jesus Christus fataal. In die Koninkryk van God is daar geen spesiale Christene nie" (Du Toit 1979:190). Die tweede 
rede waarom die benaming "individuele" verkies word, is omdat die benaming "besondere" vir 'n derde groepering van genadegawes gereserveer word.

Die derde groepering, waar die individuele charismata eintlik 'n bietjie kategories gesorteer word, kan dan die besondere ampte van die kerk genoem word. Uit so 'n sistematiese indeling, blyk dat die individuele charismata intiem verbind is, en selfs geìdentifiseer kan word, met die besondere ampte (Du P Beukes 1980:1, 16; vgl 1 Tim 4:14; $2 \operatorname{Tim} 1: 6 ; 1$ Kor 12:28; Ef 4:11).

\section{AMPTE}

Daarom moet hier 'n kort woord oor die ampte eers gesê word. Daar is verskeie voorbeelde om aan te toon dat die ampte, soos ons dit gewoonlik Nuwe-Testamenties fundeer, eintlik teruggaan na die Ou Testament (Engelbrecht 1979:11-14). So is Dawid byvoorbeeld ook gesalf en daama was die Gees met hom - soos in Jesus se geval. Dawid was gesalf om die Ou-Testamentiese kerk te dien met die gawes van regering, profesie en die digkuns (1 Sam 16:13). Wanneer ons die genadegawes min of meer in die bekende drie kategoriez indeel, is die bedoeling nie dat elke genadegawe net deur een of ander besondere ampsdraer beoefen mag word nie.

Maar uit die Nuwe Testament blyk ook dat God nie net genadegawes aan die ampsdraers soos die dienaars van die Woord, die ouderlinge en diakens gee nie, maar dikwels ook aan gemeentelede wat nie dén van dié drie ampte beklee nie. Daar is byvoorbeeld cen gawe wat bekend staan as die gawe van "uitdeel" wat volgens Romeine 12:8 "in opregtheid" moet gebeur. Die Griekse woord daar is metadidous wat eintlik beteken: "om te gee." En nou se die Bybel vir ons dat "om te kan gee" ook 'n gawe van die Heilige Gees is. 'n Mens kry nou maar partykeer mense wat as hulle moet gee en veral as hulle hulle beursie moet oqpmaak om vir die kerk te gee, dan kry hulle swaar.

(Engelbrecht 1979:13)

Die apostelamp is die fundamentele. Daaruit differensieer verskillende ampte of funksies, soos in die kerk nodig is. Die evangeliste-amp is waarskynlik die opvolging van die apostelamp. Daar is wel prinsipiele verskille tussen die apostel- en die 
evangeliste-amp, soos byvoorbeeld dat die apostels eenmalig was en deur Christus self geroep is - 'n geroepenheid van persone wat aan sekere kwalifikasies voldoen waarvan sommige vandag onmoontlik is. Die evangeliste is aanvanklik deur die apostels toegerus en beklee 'n prinsipieel-voortdurende amp. In 'n sendingsituasie kom 'n ooreenkoms tussen die apostels van toentertyd en evangeliste van alle tye, na vore. Dit is dat in die evangeliste-amp alle ampte gekonsentreer is en daarvandaan uit differensieer. Die differensiasie verloop langs profetiese, priesterlike en koninklike grondlyne.

\section{INDIVIDUELE GENADEGAWES}

Die individuele genadegawes kan dan naastenby soos volg ingedeel word:

\subsection{Profetiese genadegawes}

- $\quad$ Profesie (Rom 12:7; 1 Kor 12:10; 14:3)

- Wysheid (1 Kor 12:8)

- Voorgaan (Rom 12:8)

- Lering (Rom 12:7; 1 Kor 12:29)

- $\quad$ Glossolalie (gloss $a=$ tong, taal; lalein $=$ om te spreek - Hand $2 ; 10: 46 ; 19: 6 ; 1$ Kor 12-14)

- Uitleg van tale (1 Kor 12:10)

\subsection{Priesterlike genadegawes}

- $\quad$ Barmhartigheid (Rom 12:8)

- $\quad$ Uitdeling (Rom 12:8)

- $\quad$ Bediening (Rom 12:7; 16:1; 1 Kor 12:5; 16:15)

- Helpers (1 Kor 12:28)

\subsection{Koninklike genadegawes}

- Geloof (1 Kor 12:9). Hier word nie die algemene Christelike geloof bedoel nie, maar dié wat aan sommige mense geskenk word om wonderwerke te verrig (Bloem 1967:145)

- $\quad$ Kragte (1 Kor 12:10 en 28) 
- $\quad$ Gesondmaking (1 Kor 12:9, 28, 30)

- Onthouding (1 Kor 7:7)

- $\quad$ Vermaning (Rom 12:8)

- $\quad$ Regeringe (1 Kor 12:28)

- $\quad$ Geeste-onderskeiding (1 Kor 12:10; Rom 2:18)

Omdat die charismata dus 'n baie duidelike Bybelse saak is, moet ons aan die een kant nie negatief-afwysend daar teenoor staan nie. Aan die ander kant moet ons wel nugter Bybels die uitwasse beoordeel. Calvyn het gereken individuele charismata kom nie meer voor nie (Calvyn 1559; Coetzee 1975:29). Maar daar word nie van die charismata, soos van die apostels, duidelik te kenne gegee dat dit eenmalig was nie. Inteendeel (Luk 10:9, 17; 1 Kor 12-14; Coetzee 1975:30)! Ons moet versigtig wees vir die streepteologie wat willekeurige strepe trek tot waar die genadegawes in die geskiedenis gegee sou wees.

Dit is ' $n$ vraag of die charismata wat gepaard gegaan het met die besondere duiwelse magsontplooiing by die koms van Christus, nie weer gepaard sal gaan met die groot duiwelse magsontplooiing voor die wederkoms nie (Coetzee 1975:31; vgl 2 Tess 2:9-10; Op 13:11-14; 11:3-6; 22:11)? Die vraag is natuurlik ook of byvoorbeeld duiwelbesetenheid, wat die genadegawe van kragtige duiwelsuitdrywing ondergaan het, net "tydens Jesus se omwandeling op aarde besonder baie na vore gekom (het)? Of herken ons dit net vandag nie meer nie?" (Van Wyk 1979:69). Was baie "duiwelsbesetenheid" nie wat vandag epilepsie genoem word nie? Sodat Jesus, om verstaanbaar te wees, tipies eie aan sy tyd, in die taal van sy tyd gepraat het. So het Jesus tog ook Aramees gepraat en nie in al of selfs in één van ons huidige of moderne tale nie (Van Wyk 1979:72).

By Jesus self sien ons dat Hy na ontvangs van die Heilige Gees baie geestelike gawes beoefen het (ta pneumatika - 1 Kor 12:1, 4). Hy het siekes genees, dooies opgewek, duiwels uitgedryf. Maar nooit het Hy in tale gespreek nie! En duiweluitdrywing, hoewel dit 'n geestelike gawe is, word nooit direk genadegawe genoem nie. Dit het reeds geblyk toe ons die sewentien genadegawes gegroepeer het. Aan sy dissipels het Jesus, sonder om dit só te noem, genadegawes (charismata - 1 Kor 12:1, 4) beloof (Matt 10:8; Mark 16:17, 18). Hierdie beloftes is vervul: Tale (Hand 2:6-11; 10:44-46; 19:6), genesings (Hand 3:6, 7; 8:6, 7; 9:33, 34; 19:11, 12; 20:7-12), opwekkings (Hand 
9:36-41; 20:9-12), slangbyte (Hand 28:1-10), duiweluitdrywing (Hand 8:7; 19:12). Omdat dit so die beeld van belofte:vervulling vertoon, kan ons simpatie hê vir die standpunt dat dié genadegawes nie ewe sterk vir alle tye en plekke bedoel was nie. Tog moet ons onthou dat niemand en niks God verbied om hierdie genadegawes nog te gee nie, of weer te gee nie. Maar ons kan natuurlik God ook nie dwing tot byvoorbeeld genesingswonders (Velthuysen 1979:54), glossolalie (Van Zyl 1979:48) en duiweluitdrywing (Van Wyk 1979:67) nie.

\section{DOOP MET DIE HEILIGE GEES}

Die basiese misvatting van die charismatiese bewegings, wat na sy historiese verskyningsvorm 'n veelvuldigheid openbaar, is dat elke gelowige enkeling vandag op een of ander wyse met die Heilige Gees "gedoop" moet wees - en dan dergelike wonderlike dinge moet kan doen. Maar die Bybelse gedagte van doop met die Heilige Gees, wat sewe maal in die Nuwe Testament voorkom (Matt 3:11; Mark 1:8; Luk 3:16; Joh 1:33; Hand 1:5; 11:16; 1 Kor 12:13) dui uitsluitlik “op die uitstorting van die Heilige Gees op Pinksterdag" (Du P Beukes 1979:31).

Paulus gee in 1 Korintièrs 14:39 'n baie belangrike riglyn wat die kerk tot vandag toe moet toepas. Twee charismata word genoem: profesie en glossolalie. Met ywer moet elke gelowige die genadegawe van profesie najaag. "'n Profeet is iemand wat die gawe het om die hand en wil en doel van God in die bestaan en die geskiedenis van sy volk raak te sien en suiwer te verkondig" (Coetzee 1975:31). Die profesie is vir die opbou van die gemeente onontbeerlik (1 Kor 14:1, 3-5, 12, 18, 19, 24; 1 Tess 5:19-21).

Net so belangrik die gebod tot profesie is, is ook die verbod om nie te verhinder dat in tale gespreek word nie (Coetzee 1975:31). By profesie word positiwiteit gestel, by glossalalie word neutraliteit, nie negatiwiteit nie, gestel. Sommige is van mening dat die glossolalie ná die Nuwe-Testamentiese tyd met die Montanisme afgesluit is. Die

pinksterbewegings se talespraak sou dus nie egte glossolalie wees nie, maar kunsmatig (Grosheide 1958:242). Daar bestaan ook getuienis ten dien effekte (Eppstein 1974:3). Met die egte glossolalie was dit nie die bedoeling dat God nuwe openbaringe bring nie. Dié is volledig in sy Woord. "Wel is dit 'n teken (semeion) ... vir die ongelowiges - 'n manifestasie van die Gees om hulle die werking van God in sy kerk te laat sien. Maar 
daarom is orde hierby ook so belangrik! (1 Kor 14:22, 23)" (Coetzee 1975:31). Profesie is met die oog op die gelowiges, glossolalie met die oog op die ongelowiges (Engelbrecht 1979:14; Van Zyl 1979:48). En dan is dit nog waardeloos - tensy dit uitgelê word. Omdat die glossolalie nie openbaringsinhoud het nie maar 'n teken is, het die hermeneutiek van die genadegawe van die uitleg van tale in hierdie verband sekerlik sy betekenis rondom die tekenkarakter, ook tot eie stigting (1 Kor 14:4).

'n Verdere riglyn in ons beskouing van die charismatiese bewegings, is om te onthou dat geen spesifieke individuele genadegawe een van die notae ecclesiae is nie. Die geesdrywers verhef spesifieke genadegawes tot kenmerke van die ware Christen. Dit is wel waar dat elke Christen ook persoonlik moet voldoen aan die kenmerke van die ware kerk vir sover van toepassing op 'n persoon (vgl NGB 29). Maar met die charismata is dit volgens die Bybel tog anders. Juis die differensiasie, wat die ontbreking van sekere genadegawes by sekere gelowiges veronderstel, word beklemtoon (1 Kor 7:7; $12: 4,7,11,29,30)$.

Die charismatiese bewegings se vereiste tot ware Christenskap veronderstel 'n krisisbekering wat met die reeds gemelde doop met die Heilige Gees moet gepaardgaan. Wat bekering betref moet ons egter onthou dat mense op verskillende maniere tot die ware geloof kom: krisis aan die begin (Paulus), krisis in 'n proses (kamerling van Etiopiē), spasmodies (Petrus), gradueel of trapsgewys (Johannes, Timoteus).

\section{KENMERKE EN EIENSKAPPE}

Die sogenaamde doop met die Heilige Gees en die krisisbekering besorg aan die charismatiese bewegingmense veral drie opmerklike kenmerke. Die eerste kenmerk is 'n kragdadigheid. Dit word geopenbaar of beoefen in talespraak, wondergenesings en duiwelbeheer (De Wet 1979:23). Soms word 'n duiwel, soos die duiwel van naelbyt, waardeur 'n jong man sy naels opgeěet het, met 'n vreeslike gestoei en geweld in die konsistorie uitgedryf (De Wet 1979:21). Vanuit hierdie eerste kenmerk van kragdadigheid vloei die eienskap van oordrewe menslike aktivisme (De Wet 1979:22). God word as 't ware eenkant toe gelei terwyl die mens self die werk ter hand neem. Omdat die kragdadigheid by elke "gedoopte" anders funksioneer omdat elkeen 'n eie individuele ervaringsdoop ondergaan het, lei dit tot ' $n$ sieklike individualisme. 
Elkeen van hierdie mense is in die grond van die saak eintlik 'n baie eensame wese, want hy is in die hele werreld eintlik die enigste van sy soort. Een van die ou teoloe het van homself vertel: dat hy met sy eerste bekering so heilig was dat selfs die engele in sy teenwoordigheid skaam gekry het. Dan sê hy dat hy die Vader dank dat hy hom kon bekeer van daardie bekering sodat hy 'n Christen en 'n gelowige kon word. Dit sal die charismatikers goed doen om van hierdie getuienis van Kohlbrugge, kennis te neem

(De Wet 1979:22)

Die tweede kenmerk van die charismatici vanweě die sogenaamde doping met die Heilige Gees, is hulle eiesoortige byeenkomsliturgie. Die Woord: antwoord of dialogiese karakter van die kerklike liturgie, gaan by hulle verlore en word vervang met ' $n$ byeenkoms van godsdienstige belewing waarin die glossolalie, genesings en duiweluitdrywery die vernaamste gestaltes word (De Wet 1979:26).

Op grond van die doping met die Heilige Gees en die geloof dat bulle nou normatief deur die Gees gelei word, word die Bybel nie meer soseer normatief hanteer nie maar modelmatig. Hierdie derde kenmerk, biblisistiese fundamentalisme, sien die Bybel as 'n handboek van modelle wat net so nageboots moet word (De Wet 1979:25). Met begeestering word op die byeenkomste kragtig op genesings gekonsentreer - om soos Jesus te genees! Maar tog probeer hulle (nog nie?) om dooies op te wek of see-storms te gebied nie!

'n Volgende eienskap van die charismatici, soos voortvloeiend uit die voorafgaande, is hulle Pneumamonisme of Geesmonisme. Die Gees alleen het alle leiding oorgeneem. Paulus stel egter voorop dat die eerste werking van die Gees die ware en suiwere kernbelydenis is: Jesus is die Here (1 Kor 12:3). Voordat Paulus dan verder gaan om die genadegawes in 1 Korintiers 12-14 te bespreek, wys hy eers in 1 Korintiěrs 12:4-6 op die verband van die drie-enige God tot die genadegawes: "Die charismata (genadegawes) van die Gees (pneuma) in die gemeente is tegelykertyd ook die diakonoi (bedieninge) van die Here Christus (kurios) aan die gemeente; asook die energemata (werkinge) van God die Vader (theos) onder die gemeente" (Coetzee 1975:35). Die belydeniskriterium van die suiwere leer, is dus belangrik om te bepaal of dit 'n goeie 
geestesgawe is (1 Joh 4:1). Anders kan ons die toestand kry wat na alle waarskynlikheid in die Korintegemeente was, dat sekere persone in 'n ekstatiese toestand Jesus 'n vervloeking noem (Du Toit 1979:194).

Uit die charismatici se algemene optrede blyk dat 'n kerklose godsdienstigheid 'n verdere eienskap van hulle word (Van der Westhuizen 1980:17). Hulle wil wel nie soos die klassieke sektarisme van die kerklike organisasie afskei nie. Hulle wil hulle dwaling ongesiens in die kerklike organisasie handhaaf (De Wet 1979:27). Hulle wil die organisatoriese struktuur, wat die dooie lyf en deeg is, se siel en suurdeeg wees (De Wet 1979:25). Wat Eppstein oor "one of the characteristics of the New Theology" opmerk, is hier van toepassing: "The church of the Spirit versus the institutional church" (Eppstein 1974:50).

Wanneer die suiwere leer omgeruil word vir die vereniging rondom bepaalde ervarings, is dit te verstane dat kerkregtelike ordeninge nie veel sê nie. "De leer verdeelt. De ervaring verenigt" (Redactie 1979:948). In die stadium dat leerstelling, belydenis en kerkorde vervaag het, is dit nie moeilik om die hand van gemeenskaplike ervaring oor alle grense heen na mekaar toe uit te steek nie.

\section{EKUMENIES}

Hoe merkwaardig dan ookal, word verbintenisse aangeteken tussen charismatici in die Rooms-Katolike Kerk en die Protestantse kerke via die ekumene (Van der Westhuizen 1980:17, 40; Redaksie 1979). Verbintenisse met ortodokse kerkgroepe wie se oorsprong rondom 1054 se filioque-probleem lê, is natuurlik goed denkbaar. Nog erger word verbintenisse aangegaan tussen charismatici en Zen-Boeddhisme en Transendente Meditasie (Maris s a:860). Nog die ergste is die verbintenisse tussen charismatici en revolusionêres en Marxiste (Vermaat 1977:124, 275, 303, 304; Redaksie 1979).

Vanwez die oorsprong van die charismatiese bewegings, is twee dinge reeds baie duidelik - dat hulle wederdopers is of word en as "change agents" funksioneer. Die geskiedenis van die charismatiese bewegings toon dat hy, soos De Wet sê, 'n klein Amerikanertjie is wie se voorouers die Pentecostal Movement en die New Pentecostal Movement is (De Wet 1979:19). Hieruit is enersyds die pinkstergroepmatige weder- 
dopery van sogenaamde doop met die Heilige Gees te verklaar, en andersyds weerspieel die "movement" die aktiwiteit van beweging om veranderings te bewerkstellig.

Die beweging se ingesteldheid op verandering ly aan dieselfde siekte wat vandag byna ekumenies gediagnoseer kan word: hoenderlogika. Hiervolgens verloop die saak so: Christelikheid bring menslikheid - daarom is alle humanisering Christelik! Verlossing bring bevryding - daarom is alle bevryding verlossing! God se ingrype in die geskiedenis bring verandering - daarom is alle verandering God se ingrype! So word die vure van die brandstigting vir voorbrande van verandering, vure van die Heilige Gees! Aspirin verlig pyn - daarom is alles wat pyn verlig aspirin! Hierdie hoenderkoplogika, te ongelooflik om waar te wees, is 'n feit (Pont 1979:82; Van der Westhuizen 1977:21; Graafland 1978:100; Stott 1977:104; vgl ook Op 13:13).

\section{SLEUTELS}

Daar moet aan vier sleutels vasgehou word in die hantering van die onderhawige individuele genadegawes.

Eerstens moet die weg waarlangs die genadegawes beoefen word, dié van die Christelike liefde wees (1 Kor 13). Daar mag dus nie met spesifieke individuele genadegawes gespog word nie (1 Kor 12:12-27; vgl Coetzee 1975:32).

Tweedens is dit 'n vereiste dat die genadegawes nuttig moet wees in die diens aan die één liggaam van Christus - die kerk (Du Toit 1979:195; vgl 1 Kor 12:7).

Derdens moet die prioriteite vir die nuttigheid tot die oikodome, die opbou van die gemeente, vasgestel en gevolg word (1 Kor 3:9; 1 Kor 12:31). Die beste gawes, waarvoor ons ons moet beywer (1 Kor 12:31), word bereken volgens die heilige pragmatisme van Paulus (Du Toit 1979:199), naamlik nuttigheid en ordelikheid (1 Kor 12:7; 1 Kor 14:33).

Omdat die riglyn van ordelikheid by die vasstelling van prioriteite so hoog aangeslaan word, word die noue samehang tussen individuele genadegawes en die kerklike ampte beklemtoon, soos reeds aangedui. Die volgende vraag is myns insiens belangrik: "Moet daar nie veel meer werksdifferensiasie in die ouderlingamp kom volgens die gawes nie; dat die een veral op daardie terrein arbei, terwyl die ouderling met die gawe van profesie meer op die huisbesoek hom toespits nie?" (Coetzee 1975:33; Du P Beukes 


\section{Charismatlese bewegings}

1980:1). As ons iets dergeliks nie doen nie, is ons nie goeie "ekonome" van die veelvuldige genade van God nie (1 Pet 4:10).

Vanuit die nuttigheidsoogpunt en die ordelikheidsoogpunt kan die samehang tussen die aanvanklik geformuleerde drie hooftipes van genadegawes, soos volg gestel word: Die individuele genadegawes moet die besondere genadegawes (die ampte) dien om die algemene genadegawe van die versoening te bedien.

Die vierde sleutel in die hantering van die individuele genadegawes, is om te besluit wat waarskynlik die finale vraag in hierdie verband aan ons sal wees. Sal dit wees: Hoeveel en watter individuele genadegawes het jy ontvang? Of sal dit wees: "Het die vrug van die Gees in jou lewe tevoorskyn gekom?!" (Coetzee 1975:35).

"Maar die vrug van die Gees ... is liefde, vreugde, vrede, geduld, vriendelikheid, goedhartigheid, getrouheid, nederigheid en selfbeheersing" (Gal 5:22).

\section{SPIRITUALITEIT}

Met die voorafgaande as teologiese perspektief waarteen ons die charismatiese neigings in die Nederduitsch Hervormde Kerk kan beoordeel, word dit duidelik dat die beoordeling self ook billike en gebalanseerde perspektief moet behou.

Met spiritualiteit, wat huidig 'n modewoord geword het, word egter nie die charismatiese bewegings bedoel nie. Hoewel die charismatici sekerlik reg het om aanspraak op spititualiteit te maak, kan hulle nie eksklusiewe beslag op die begrip lê nie. Net so min kan hulle ook eksklusiewe beslag lê op charisma en charismata.

Die verskynsel in die Hervormde Kerk dat sommige predikante, wat altyd gewillige volgelinge in gemeentes vind, die eredienste en geloofslewe met spontane inisiatiewe buite die kerkordelikheid en kerklike etos om omvergooi, kan dalk deels teruggevoer word na strakke vermyding van spiritualiteit reeds in die vormingsjare van die teologiese opleiding. Dit is dus goed dat die Hervormde Kerk en die teologiese opleiding hieraan grondige aandag gee.

Wat die teologiese opleiding betref, lees ons dat prof T F J Dreyer tereg sê: "Teologiese opleiding moet daarteen waak om alle aksent op die predikant se kennisfunksie en doen-funksie te plaas, terwyl sy wees-funksie met die oog op die kweek van 'n egte Bybelse spiritualiteit en die vorming van 'n eie identiteit binne sy tradisie, agterwee 
gelaat word" (Dreyer 1998a:5). Dieselfde standpunt is toe ook deur die destydse dekaan, prof J H Koekemoer gestel (Koekemoer 1999:5).

'n Mens verneem deesdae dat sommige Reformatoriese kerke gemeentes het, waar die preekstoel uitgebreek is. Die prediking word vervang met individuele belewenisse wat in die erediens spektakulêr tot uiting kom. Psalms en Gesange word vervang met vervoeringliedjies wat daarop gerig is om die singer te laat lekker voel en nie daarop gerig is om die Heer te loof as 'n weerklank van sy Woord nie.

Dr Wim Dreyer stel tereg:

Die Nederduitsch Hervormde Kerk mag nooit die verkondiging van die evangelie en die Woord vervlak of verwaarloos nie. Die Bybel leer ons dat dit instrument in die hand van die Heilige Gees is om mense te lei tot 'n egte geloof, 'n egte verhouding met God, 'n egte spiritualiteit. Geen truuks (ook nie op die kansel nie) kan tot egte spiritualiteit lei nie. Slegs die Heilige Gees kan, deur die verkondiging van die Woord, dit doen

(Dreyer 1998b:2)

\section{POSTMODERNISME}

Waar die Nederduitsch Hervormde Kerk reeds voorlopige erns begin maak het met die evaluering van die verskynsel van die charismatiese beweging, is dit dringend nodig dat daar diepgang verleen sal word in die teologiese opleiding, die handhawing van kerklike ordelikheid in die gemeentes en die algemene toerusting ten opsigte van die ontsporing.

Die erns word onderstreep deur die gees van die tyd en die spesifieke omstandighede waarin ons vandag in Suid-Afrika lewe. Tereg sê prof A P B Breytenbach dat die publiek 'n kettingwinkelmentaliteit ontwikkel het - ook op geestelike gebied: "Mense loop en wil bedien word by die plek van hulle keuse" (Breytenbach 1997:3).

Hierdie mentaliteit, hierdie tydsomstandighede en tydsgees voed die postmodernisme wat met die verlede wil breek, wat twyfel aan sekerhede, en ook negatief staan teenoor kennis en heersende denksisteme. Die heersende meesterkode, of denksisteem wat die gemeenskap beheer, word in die postmodernisme vervang met "ervaring van enkelinge, eie verstaan en belewing" (Breytenbach 1997:3). 
Waar die Grundnorm in Suid-Afrika van volke, rasse, geslagte, klasse en kerke besig is om abrupt omvergewerp te word, gesteun en gewaarborg deur sogenaamde menseregte en grondwet, staan die charismatiese spiritualiteit so aanloklik soos 'n engel van die lig.

\section{Literatuurverwysings}

Botha, S J 1985. Campus Crusade: inhoud en metodes bevraagteken. Die Hervormer 77, 10 Januarie.

Bloem, G N 1967. Die genadegawes in die Nuwe Testament. HTS 23(4), 121-151.

Breytenbach, A P B 1997. Charismatiese tendense in die Nederduitsch Hervormde Kerk van Afrika. Die Hervormer 90(16), 15 November.

Calvyn, J 1559. Institusie IV, 3, 4.

Cassidy, M 1974. Prisoners of Hope. Africa Enterprise.

Coetzee, J C 1975. Chrismata-Geestesgawes. In die Skriflig.

De Wet, J I 1979. Die Charismatiese Beweging - inleidende opmerkings. HTS 35(3\&4), 19-27.

Dreyer, T F J 1998a. Teologiese Opleiding en spiritualiteit. Die Hervormer 91(1), 1 April.

Dreyer, W A 1998b. Egte spiritualiteit. Die Hervormer 91(6), 15 Junie.

Beukes, M J Du P 1979. Besondere gawes van die Heilige Gees. HTS 35(3\&4), 28-47.

Beukes, M J Du P 1980. Die ampte in die huidige tydsgewrig met die oog op groter differensiasie. HTS 36(1\&2), 1-20.

Du Toit, A B 1979. Die Charismata. NGTT.

Engelbrecht, B J 1979. Die werk van die Heilige Gees. HTS 35(3\&4), 6-18.

Eppstein, J 1974. The Cult of Revolution in the Church. Sandton: Valiant Publishers.

Graafland, C 1978. Theologische Hoofdlijnen: Gij die eertijds verre waart ... Een inleiding tot de Gereformeerde zendingswetenschap. Utrecht: De Banier.

Grosheide, F W 1957. Charismata. Christelijke Encyclopedie, II. Kampen: Kok.

Kempff D 1974. Geloofsgenesing en tongetaal getoets. Potchefstroom: Pro Rege.

Koekemoer, J H 1999. Die Heilige Gees, spiritualiteit en teologiese opleiding. Die Hervormer 91(21), 1 Maart. 
Maris, J C [s a]. Wereldregering door Transcendente Meditatie. Getrouw 32(2).

Pont, A D 1979. Dwalings rondom die Heilige Gees. HTS 35(3\&4), 76-86.

Redactie 1979. Charismatiese Beweging. Getrouw 32(7\&8).

Redaksie 1979. Protestantse Reveil.

Stott, J R W 1977. Christian mission in the modern world. London: Falcon.

Van der Westhuizen, H G 1977. Vure van Soweto. Leer en Lewenskwessies in SuidAfrika. Junie.

Van der Westhuizen, H G 1980. Inleiding tot die Godsdienswetenskap. Studiegids: Universiteit van die Noorde.

Van Wyk, D J C 1979. Duiwelbesetenheid en Duiweluitdrywery in die lig van die Nuwe Testament. HTS 35(3\&4), 67-75.

Van Zyl, F J 1979. Die Charisma van die spreek in tale (Glossolalie). HTS 35(3\&4), 4853.

Velthuysen, G C 1979. Die problematiek rondom "gebedsgenesings" en die "genadegawes van genesing" soos wat dit in die pinksterbeweging geleer en beoefen word. HTS 35(3\&4), 54-66.

Vermaak, J A E 1977. Christus of Ideologie. Utrecht: De Banier. 